\title{
In the Mood for a Blood Donation? Pilot Study about Momentary Mood, Satisfaction, and Return Behavior in Deferred First-Time Donors
}

\author{
Klara Greffin ${ }^{a}$ Holger Muehlan ${ }^{a} \quad$ Samuel Tomczyk ${ }^{a} \quad$ Ariane Suemnig $^{b}$ \\ Silke Schmidt ${ }^{a} \quad$ Andreas Greinacher $^{c}$

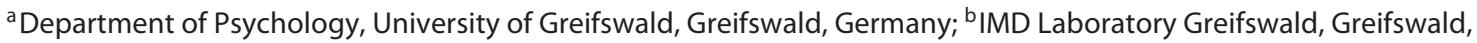 \\ Germany; ' Institute for Immunology and Transfusion Medicine, University Medicine Greifswald, Greifswald, Germany
}

\section{Keywords}

First-time donors · Initially deferred donors · Mood .

Deferral · Donor return behavior

\begin{abstract}
Introduction: To maintain a sufficient donor pool, deferred first-time donors (FTD) should be motivated to return for blood donation. This pilot study investigates how deferral affects momentary mood, satisfaction with the donation process, and subsequent return behavior to examine their potential for motivating (deferred) FTD. Methods: All of the subjects $(n=96)$ completed a first questionnaire (A1) before pre-donation assessment. Deferred FTD $(n=22)$ were asked to complete a second questionnaire (A2) immediately after deferral, while non-deferred FTD $(n=74)$ filled in the second questionnaire (A3) after blood donation. The impact of deferral, momentary mood, and satisfaction with the donation process on return behavior within 12 months was tested by calculating two path analyses, controlling for sex and age. Results: Mood $(p<0.001)$ and satisfaction with social aspects of the donation process ( $p=0.01$ ) were decreased after deferral. Deferred FTD were less likely than non-deferred FTD to return to the blood donation center within 12 months ( 60.8 vs. $36.4 \% ; p=0.043$ ). However, path analyses revealed that deferral effects on mood and satisfaction were not connected to return behavior. Instead, age had a significant influence on return behavior $(p<0.05)$ such that, overall, nonreturning FTD were older than returning FTD, regardless of their deferral status. Conclusion: Our findings suggest that mood and satisfaction with the donation process are direct-
\end{abstract}

karger@karger.com www.karger.com/tmh

Karger ${ }^{\prime \prime}=$

BOPEN ACCESS
(C) 2021 The Author(s)

Published by S. Karger AG, Basel

This article is licensed under the Creative Commons Attribution NonCommercial-NoDerivatives 4.0 International License (CC BYNC-ND) (http://www.karger.com/Services/OpenAccessLicense) tribution of modified material requires written permission. ly affected by deferral but not clearly responsible for low return rates. It seems promising to embed these variables in established health behavior models in further studies to increase the return rates of deferred FTD.

(c) 2021 The Author(s)

Published by S. Karger AG, Basel

\section{Introduction}

One of the current key challenges for health care systems is to sustain a whole-blood donor (WBD) pool sufficient to meet the transfusion demand. Demographic changes [1-3] and increasingly stringent donation criteria [4] have reduced the number of voluntary WBD in Germany. Some potential blood donors have to be deferred temporarily for a variety of reasons [5], for instance, due to aspects of the donor's health (e.g., low hemoglobin levels), behavior (e.g., sexual), or personal factors (e.g., pregnancy $[6,7])$. Especially the percentage of first-time WBD (FTD) who have to be deferred is high [7-9]. Compared to repeat donors, FTD are unfamiliar with eligibility screening and may lack awareness of how to adapt their lifestyle to meet the selection criteria [10].

Deferral at a first-time attempt to donate blood may be crucial for a donor's future donation attempts as deferred FTD are less likely to return for subsequent blood donations than non-deferred FTD [11, 12]. Custer et al. [13] found that, if they returned, deferred FTD took longer to return to donate in comparison with deferred repeat donors. In summary, deferring 
FTD seems to reduce the likelihood of them becoming frequent donors within 12 months of the initial donation attempt.

As frequency of donation in the first year is positively correlated with long-term donor retention [14], increasing the return of deferred FTD once they become eligible again is a relevant factor for donor management. As such, it is important to understand the reasons for the low return rates that occur following deferral of FTD. In a recent analysis, Davison et al. [10] provide a comprehensive review of the factors that contribute to non-return of deferred FTD. Those identified were mostly cognitive (e.g., deferred FTD lack of "a sense of mastery and competence in being able to donate blood" or role identity as a blood donor) or deferral-related (e.g., they overestimate their risk of being deferred again or misinterpret the received deferral as being permanent). However, litthe is known about the impact of donors' initial affective reactions to a deferral on their subsequent return behavior [15].

Concerning affective reactions in the context of blood donation, Hinrichs et al. [16] showed greater mood values after donation in new and repeated donors. Jansen et al. [17] confirmed these finding in FTD, with the highest values for good mood $30 \mathrm{~min}$ after donation. In contrast, an Australian group found that the emotions experienced when receiving a temporary deferral are anger, frustration, and disappointment [18].

Donation-specific dissatisfaction can hinder future blood donation [19], while satisfaction with the donation process is one of the key elements of building donor loyalty [20]. The aim of this pilot study was to investigate whether there are differences in momentary mood and satisfaction with the donation experience between first-time donors (FTD) who have been deferred and those who have not. Second, we were interested in whether any differences observed between these 2 groups impacted their return behavior within 12 months.

The following questions are addressed in the study:

1. Question 1: Do deferred and non-deferred FTD experience different changes in momentary mood?

2. Question 2: Do deferred and non-deferred FTD differ in their satisfaction with the donation process?

3. Question 3: Is there a difference in the return rates of deferred and non-deferred FTD?

4. Question 4: Do momentary mood or satisfaction with the donation process predict the return behavior of deferred and non-deferred FTD?

5. Question 5: In case a predictor can be identified in question 4, is the predictor specific for genuine FTD only?

\section{Materials and Methods}

This prospective study was conducted between March and May 2016 at the Department of Transfusion Medicine of the University Medicine Greifswald; the follow-up data was collected 12 months later. As standard practice, the eligibility of every FTD who presented at the donation center was assessed in a pre-donation assessment. Following donation, each donor received refreshments and EUR 20 to cover expenses incurred in relation to their donation (e.g., travel costs). Donors deferred at the initial pre-donation assessment did not receive refreshments or any remuneration.

\section{Recruitment of Participants}

In the context of their first donation attempt at the blood donation center of University Medicine Greifswald, all FTD have to read, fill in, and sign a standardized information form and a routine donor history questionnaire upon entering the donation center. During the study period, those documents were accompanied by an informational letter about this study, an informed consent form, and the first set of paper-and-pencil questionnaires (A1). The documents were taken single-handedly by the donors after entering the donation center. Based on this, the potential donors could decide whether to participate in this study or not. All of the donors had the chance to obtain additional information about this study by asking a staff member who was present in the waiting/ refreshment area. FTD who were interested in participating were asked to give informed consent and fill in form A1 prior to the pre-donation assessment.

\section{Inclusion Criteria}

FTD could participate in this study if they were about to give their first blood donation at the blood donation center of University Medicine Greifswald. Prior experiences at other donation centers were registered but not a cause of exclusion. The potential donors had to be between 18 and 59 years old to be available for another potential donation in the 1-year follow-up. Donors were explicitly informed that participation in this study had no impact on their eligibility to donate.

\section{Study Design}

This study comprised two different sets of questionnaires (A) for each participant. All of the participants completed A1 prior to the pre-donation assessment. Those donors who were subsequently deferred from donation were asked to complete a second questionnaire (A2) immediately after being deferred, while those allowed to donate were asked to answer their second questionnaire (A3) in the refreshment area after they had donated blood.

\section{Questionnaires}

The first questionnaire (A1) comprised the German version of the Multidimensional Mood Questionnaire short form A [MDMD SF-A; 21]. This was used to measure momentary mood on three dimensions of mood (good-bad [GB]; 4 items: content, bad, good, and uncomfortable), vigilance (awake-tired [AT]; 4 items: rested, exhausted, tired, and energetic), and agitation (calm-nervous $[\mathrm{CN}] ; 4$ items: restless, calm, uneasy, and relaxed). All of the items were responded to on a 5 -point Likert scale $(1=$ not at all, $5=$ very much). Momentary mood was represented by the summed scores for each of the dimensions of mood, vigilance, and agitation at each time point. In addition, the participants indicated whether they had ever donated blood at another donation center (yes/no), their sex (male/female), and their age (in years).

The second set of questionnaires (A2 and A3) also included the MDMQ SF-A. In addition, satisfaction with the donation process in the center was assessed in both deferred (A2) and non-deferred (A3) donors using 8 items created for this study. These items as- 
sessed FTD satisfaction with their travel to the donation center, the waiting time, the pre-donation assessment, the perceived medical care, the perceived psychosocial care (such as kindness), the service (e.g., refreshment), the ambience of the center, as well as communication between the staff and the donor. Responses to all of the items were recorded using a 4 -point Likert scale ( $1=$ totally unsatisfied, $4=$ totally satisfied).

\section{Statistics}

Statistical analyses of the data were performed using IBM SPSS Statistics 22 [22] and Mplus version 7.4 [23]. The analyses were performed with complete cases, as a missing value analysis indicated data missing completely at random. $p<0.05$ was considered statistically significant.

A mixed ANOVA with repeated measurement on time and the between-subjects factor of deferred status (deferred, non-deferred) was used to test whether deferred and non-deferred FTD experience different changes in momentary mood (question 1). Partial $\omega^{2}$ was used to report effect sizes due to the small and unequal group sizes.

After conducting principal component analysis with varimax rotation, 2 different components of satisfaction were identified. Component 1 comprised the donor's satisfaction with their travel to the donation center, the waiting time, and the pre-donation assessment (referred to as satisfaction with structural aspects; Cronbach $\alpha=0.750)$. Satisfaction with perceived medical care, perceived psychosocial care (such as kindness), service (e.g. catering), center ambience, and communication between staff and donors formed the second component (referred to as satisfaction with social aspects; Cronbach $\alpha=0.792$ ). The 2 components are represented in analyses by mean values of the associated item scores. An independent-samples $t$ test was conducted using the 2 identified factors of satisfaction to see whether deferred and non-deferred FTD differed in their satisfaction with the donation process (question 2). The Hedges $g_{s}$ was used to report effect size.

The return rates of all of the participants within 12 months after the initial donation attempt were determined using the database of the blood donation center (categorized as returned vs. did not return). The $\chi^{2}$ test was calculated to determine whether return rates differed between deferred and non-deferred FTD (question $3)$. Effect size was reported as a $\varphi$ coefficient.

To test whether momentary mood or satisfaction with the donation process predicts the return behavior of deferred and nondeferred FTD (question 4), zero-order correlations were calculated. Additionally, a first path analysis was conducted based on data of genuine FTD $(n=96)$ using a weighted least squares mean and variance adjusted estimator for the binary outcome (i.e., return). FTD are typically defined as having no prior experiences in donating blood. Model fit was evaluated via the overall goodness-of-fit $\chi^{2}$ test (an insignificant result indicates a good overall fit to the data), the root mean square error of approximation (values $<0.05$ indicate an excellent model fit, values $<0.08$ indicate an acceptable model fit), the comparative fit index and the Tucker-Lewis index (values near 1 indicate a good fit) [24].

Finally, to check whether the predictor potentially identified in question 4 is specific for genuine FTD (question 5), a second path analysis including genuine and non-genuine FTD and zero-order correlations were conducted $(n=131)$. Non-genuine FTD characterized all of participants who had prior experiences at other blood donation centers but their first blood donation at the blood donation center of University Medicine Greifswald during the time of the study. For this purpose, the first path model $(n=96)$ was expanded and non-genuine FTD $(n=35)$ were included as an additional variable (referred to as FTD status). This second path analysis was also conducted using a weighted least squares mean and variance adjusted estimator for the binary outcome.

\section{Results}

One hundred sixty-four participants were enrolled, and 131 of them provided data suitable for analysis. The reasons for drop out and exclusion are presented in online supplementary Table A (for all online suppl. material, see www.karger.com/doi/10.1159/000514016).

\section{Sample}

In the remaining sample $(n=131), 26.7 \%(n=35)$ of the participants had prior experiences at other donation centers (referred to as non-genuine FTD). Of the genuine FTD, $22.9 \%$ were deferred $(n=22$; mean age 26.09 years; $\mathrm{SD}=9.05 ; 77.3 \%$ women and $22.7 \%$ men). The remaining group of non-deferred FTD $(n=74)$ was comprised of $58.1 \%$ women and $41.9 \%$ men, with a mean age of 25.11 years $(\mathrm{SD}=9.96)$. The maximum deferral length was 4 months, so all of the deferred donors were able to come back within the follow-up period. The following results are based on analyses of genuine FTD $(n=96)$. Only the results of the extended path model were calculated using data from genuine and non-genuine FTD $(n=131)$.

\section{Momentary Mood}

Table 1 presents descriptive statistics for the summed scores on the MDMQ SF-A and participants' mean scores on the measures of satisfaction. A mixed ANOVA showed a significant interaction between time and group on $\operatorname{mood}\left(F[1,89]=46.46 ; p<0.001, \omega p^{2}=0.33\right)$ indicating a poorer mood in FTD after deferral (mean $=16.25, \mathrm{SD}=$ 4.25) than in FTD after donation (mean $=18.49, \mathrm{SD}=$ 1.99, Q1). Furthermore, the results of the mixed ANOVA showed a significant main effect on agitation indicating that all FTD became more calm over time $(F[1,89]=$ 13.37; $\left.p<0.001, \omega p^{2}=0.12\right)$. Finally, deferred and nondeferred FTD did not differ in terms of vigilance (Fig. 1).

\section{Satisfaction}

An independent-samples $t$ test showed that deferred and non-deferred FTD did not differ in their satisfaction with the structural aspects of the donation process $(t[93]$ $=0.27 ; p=0.786$ ). However, they did differ in their satisfaction with the social aspects of the donation $(t[24.05]=$ $-2.20 ; p=0.038, \mathrm{~g}_{\mathrm{s}}=0.72$ ), with non-deferred FTD being more satisfied than deferred FTD (question 2). Finally, a $\chi^{2}$ test showed a significant difference in the return rates of deferred and non-deferred FTD $\left(\mathrm{x}^{2}[1, n=96]=4.10\right.$; $p=0.043)$, with $36.4 \%$ of deferred FTD $(n=8)$ and $60.8 \%$ of non-deferred FTD $(n=45)$ returning within 12 months of their initial donation attempt (question 3 ).

\section{Return Behavior}

Zero-order correlations are presented in online supplementary Tables B and C. A significant correlation between 


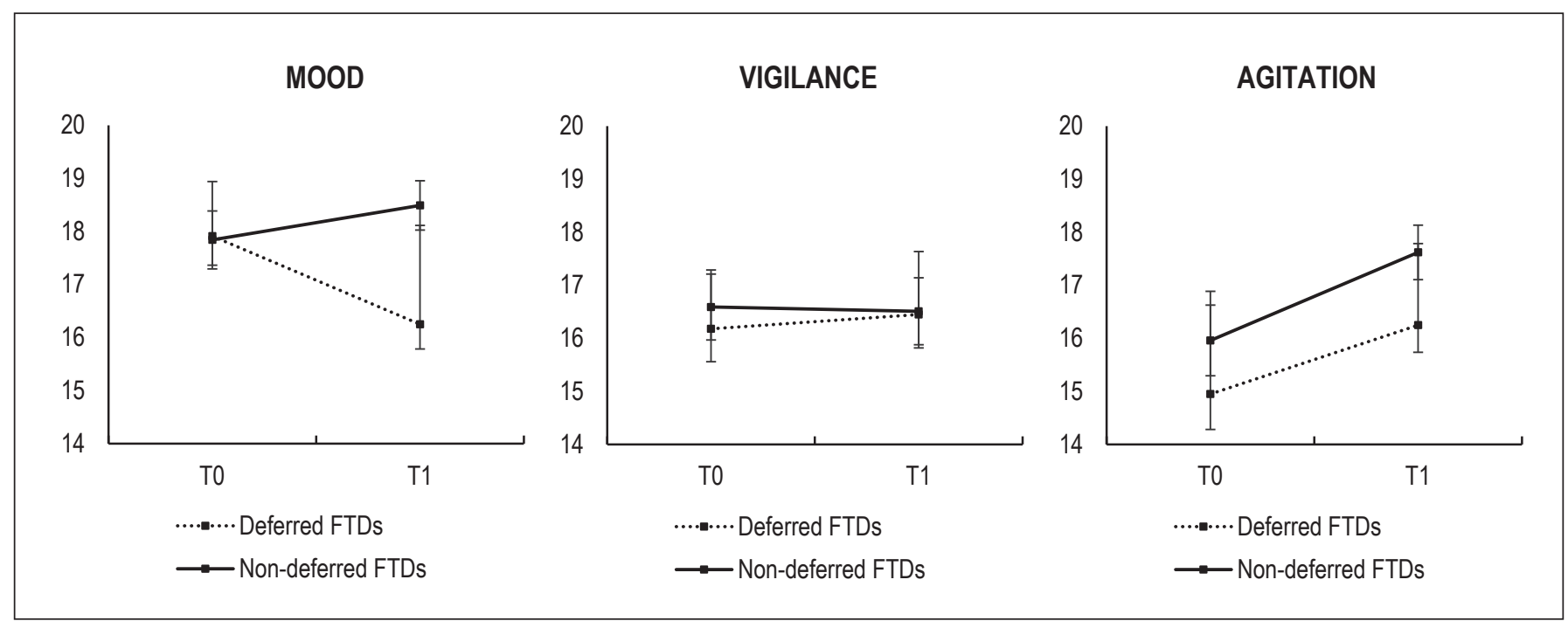

Fig. 1. Mood, vigilance, and agitation in initially deferred FTD and non-deferred FTD before the pre-donation assessment $\left(\mathrm{T}_{0}\right)$ and after deferral/donation $\left(\mathrm{T}_{1}\right)$.

Table 1. Descriptive statistics of momentary mood and satisfaction for genuine deferred FTD and non-deferred FTD

\begin{tabular}{|c|c|c|c|c|c|c|}
\hline & \multirow[t]{2}{*}{$N$} & \multicolumn{2}{|l|}{$\mathrm{T}_{0}$} & \multirow[t]{2}{*}{$N$} & \multicolumn{2}{|l|}{$\mathrm{T}_{1}$} \\
\hline & & mean & SD & & mean & SD \\
\hline \multicolumn{7}{|l|}{ Deferred FTD ${ }^{\mathrm{a}}$} \\
\hline \multicolumn{7}{|l|}{ MDMQ SF-A } \\
\hline Mood & 22 & 17.91 & 2.47 & 20 & 16.25 & 4.25 \\
\hline Vigilance & 22 & 16.18 & 2.65 & 20 & 16.45 & 2.70 \\
\hline Agitation & 22 & 14.95 & 4.63 & 20 & 16.25 & 4.25 \\
\hline \multicolumn{7}{|l|}{ Satisfaction } \\
\hline Structure & & & & 21 & 3.74 & 0.28 \\
\hline Social & & & & 21 & 3.70 & 0.37 \\
\hline \multicolumn{7}{|c|}{ Non-deferred FTD ${ }^{b}$} \\
\hline \multicolumn{7}{|c|}{ MDMQ SF-A } \\
\hline Mood & 73 & 17.84 & 2.39 & 71 & 18.49 & 1.99 \\
\hline Vigilance & 73 & 16.59 & 2.71 & 71 & 16.51 & 2.71 \\
\hline Agitation & 73 & 15.96 & 2.90 & 71 & 17.62 & 2.20 \\
\hline \multicolumn{7}{|l|}{ Satisfaction } \\
\hline Structure & & & & 74 & 3.71 & 0.56 \\
\hline Social & & & & 74 & 3.88 & 0.22 \\
\hline
\end{tabular}

$\mathrm{T}_{0}$, pre-donation; $\mathrm{T}_{1}$, post-donation. ${ }^{\mathrm{a}}$ The number of subjects is $20-22 .{ }^{\mathrm{b}}$ The number of subjects is $71-74$.

deferral and return behavior $\left(\mathrm{r}=-0.21^{*}\right)$ as well as agitation after deferral/donation and return behavior $\left(\mathrm{r}=0.21^{*}\right)$ could be observed in the sample of genuine FTD $(n=96)$. These results were not significant in the sample of genuine and non-genuine FTD $(n=131)$, while the correlation between age and return behavior $\left(\mathrm{r}=-0.18^{*}\right)$ became significant.

As shown in Table 2, models 1 and 2 showed a very good model fit. The first path model (Fig. 2) based on genuine FTD data only $(n=96)$ indicates the impact of deferral on $\operatorname{mood}(p<0.001)$, agitation $(p<0.05)$, and satisfaction with the social aspects of donation $(p<0.01)$. However, no effects of mood, agitation, or satisfaction with the social aspects of donation on return behavior were identified (question 4 ). Instead, age had a significant influence on return behavior $(p<0.05)$ such that, overall, non-returning FTD were older (mean $=27.30, \mathrm{SD}=$ $11.24)$ than returning FTD (mean $=23.74, \mathrm{SD}=8.06$ ), regardless of whether they were deferred or not.

A second path model (Fig. 2; question 5) based on data of genuine and non-genuine FTD $(n=131)$ also indicated 


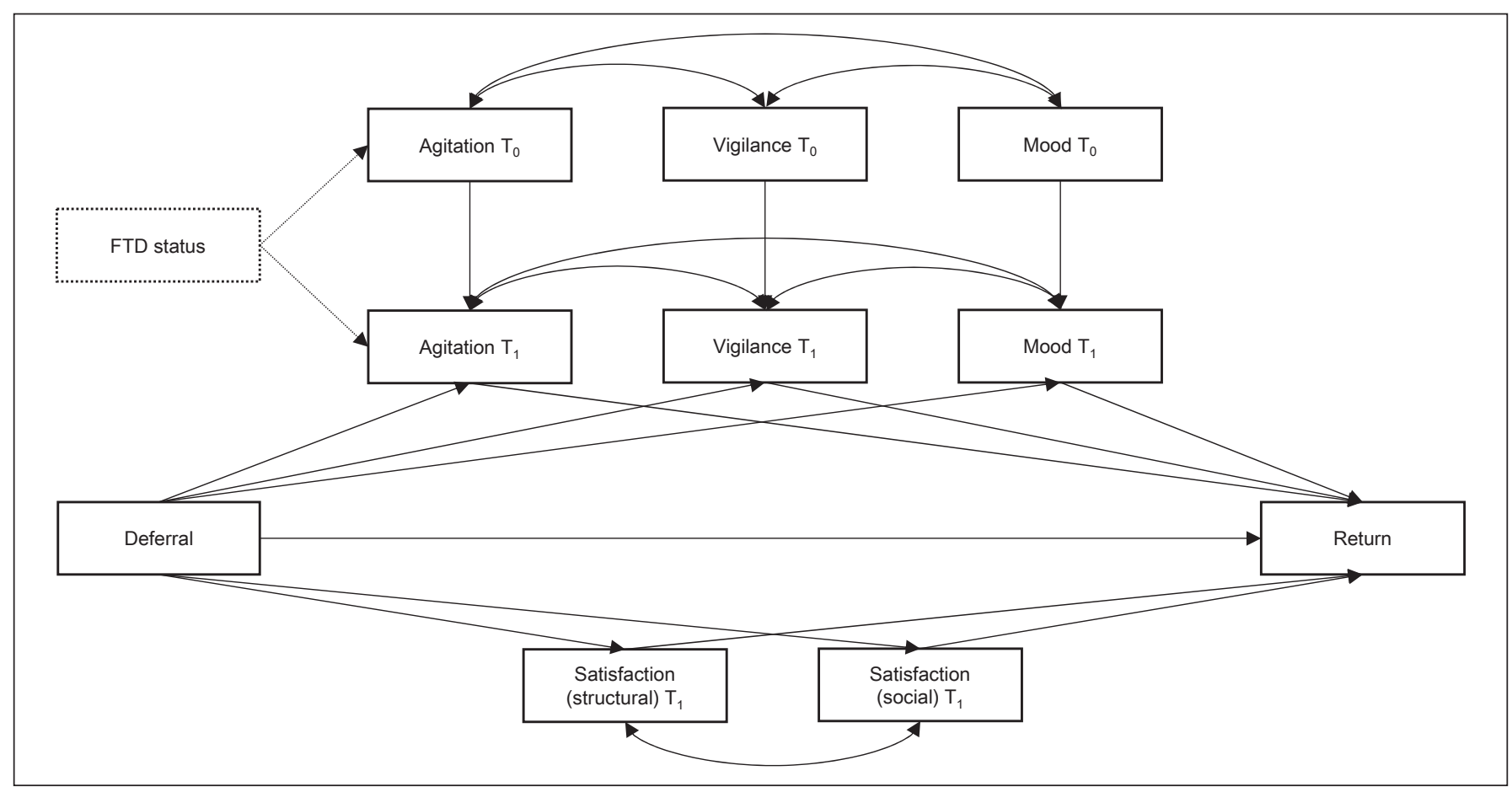

Fig. 2. Model of the calculated path analyses, statistically controlled for age and sex. Subscript numbers indicate time points pre-donation $\left(\mathrm{T}_{0}\right)$ and post-donation $\left(\mathrm{T}_{1}\right)$, with the dotted variable "FTD status" indicating the inclusion of FTD status (genuine/non-genuine) for the first $(n=96)$ and the second path model $(n=131)$.

Table 2. Results of path models with covariates

\begin{tabular}{|c|c|c|c|c|}
\hline Parameter & $\begin{array}{l}\text { Path model } 1^{\mathrm{a}} \\
(n=96)\end{array}$ & $95 \% \mathrm{CI}$ & $\begin{array}{l}\text { Path model } 2^{\mathrm{b}} \\
(n=131)\end{array}$ & $95 \% \mathrm{CI}$ \\
\hline$\chi^{2}$ (goodness-of-fit test) & $13.526(\mathrm{df}=12)$ & - & $28.682(\mathrm{df}=23)$ & - \\
\hline CFI & 0.992 & - & 0.981 & - \\
\hline TLI & 0.958 & - & 0.939 & - \\
\hline RMSEA & 0.036 & 0.000 to $0.114^{+}$ & 0.043 & 0.000 to $0.088^{+}$ \\
\hline Deferral agitation $\mathrm{T}_{1}$ & $0.220^{*}$ & 0.045 to 0.396 & $0.343^{* * *}$ & 0.207 to 0.480 \\
\hline Deferral vigilance $T_{1}$ & 0.014 & -0.204 to 0.231 & 0.140 & -0.032 to 0.312 \\
\hline Deferral mood $\mathrm{T}_{1}$ & $0.346^{* * *}$ & 0.179 to 0.513 & $0.406^{* * *}$ & 0.275 to 0.538 \\
\hline Deferral satisfaction (structural) $\mathrm{T}_{1}$ & -0.040 & -0.405 to 0.324 & 0.069 & -0.178 to 0.316 \\
\hline Deferral satisfaction (social) $\mathrm{T}_{1}$ & $0.295^{* *}$ & 0.129 to 0.461 & $0.377^{* * *}$ & 0.244 to 0.511 \\
\hline Deferral return & 0.186 & -0.085 to 0.458 & 0.134 & -0.111 to 0.378 \\
\hline Agitation $\mathrm{T}_{1}$ return & 0.276 & -0.083 to 0.635 & 0.201 & -0.135 to 0.536 \\
\hline Vigilance $\mathrm{T}_{1}$ return & 0.126 & -0.178 to 0.430 & 0.141 & -0.125 to 0.408 \\
\hline Mood $\mathrm{T}_{1}$ return & -0.181 & -0.487 to 0.124 & -0.204 & -0.504 to 0.097 \\
\hline Satisfaction (structural) $\mathrm{T}_{1}$ return & -0.018 & -0.241 to 0.206 & 0.060 & -0.168 to 0.289 \\
\hline Satisfaction (social) $\mathrm{T}_{1}$ return & 0.171 & -0.134 to 0.477 & 0.072 & -0.186 to 0.330 \\
\hline Age return & $-0.244^{*}$ & -0.477 to -0.011 & $-0.257^{*}$ & -0.464 to -0.049 \\
\hline Sex return & -0.037 & -0.293 to 0.220 & -0.119 & -0.342 to 0.103 \\
\hline
\end{tabular}

Standardized model results. CFI, comparative fit index; TLI, Tucker-Lewis index; RMSEA, root mean square error of approximation; $\mathrm{T}_{1}$, post-donation. ${ }^{*} p<0.05 .{ }^{* *} p<0.01 .{ }^{* *} p<.001(90 \% \mathrm{CI}) .{ }^{\mathrm{a}}$ Includes genuine FTD $(n=96) .{ }^{\mathrm{b}}$ Includes genuine and non-genuine $\operatorname{FTD}(n=131)$.

an impact of deferral on mood $(p<0.001)$, agitation $(p<$ $0.001)$, and satisfaction with the social aspects of donation $(p<0.001)$. However, no effects of mood, agitation, or satisfaction with the social aspects of donation on return behavior were identified. Still age had a significant influence on return behavior $(p<0.05)$ such that non-returning FTD were older (mean age $=28.95$ years, $\mathrm{SD}=10.97$ ) than returning FTD (mean age $=25.25$ years, $\mathrm{SD}=9.40$ ). 


\section{Discussion}

In this pilot study, we sought to test how deferral affects the initial affective reaction, satisfaction with the donation process, and subsequent return behavior of FTD. Primarily, we investigated the impact of initial deferral of FTD on momentary mood, consisting of the three dimensions mood, vigilance and agitation, as well as satisfaction with structural and social aspects of the donation process. Our findings suggest that mood and satisfaction with social aspects of donation were worse in deferred FTD than in nondeferred FTD, while vigilance, agitation, and satisfaction with structural aspects of donation did not differ between the groups (questions 1 and 2). Second, we found that deferred FTD were less likely than non-deferred FTD to return to the blood donation center within 12 months (question 3). Even though there were differences in momentary mood and satisfaction with social aspects of the donation process between deferred and non-deferred FTD, only deferral and agitation after deferral/donation correlated significantly with return behavior in the sample of genuine FTD (question 4), whereas age correlated significantly with return behavior in the sample of genuine and non-genuine FTD. Nevertheless, only age was identified as a significant predictor in both path models, with older FTD being less likely to return for a subsequent donation (question 5).

The impact of the first donation experience on mood is in agreement with previous findings [16-18, 25], such as that a successful donation caused an increase in mood whereas the experience of deferral caused a decrease in mood. As we only examined mood, and not distinct emotions, it is not possible to specify which emotions were felt by deferred FTD in this study. However, as hurt [25] and all deferral-related emotions identified by Gemelli et al. [18] are conceptualized as negative emotions, it seems plausible that they are the reason for the observed mood reduction. Although our data does not show a direct connection between momentary mood and return behavior, as it is temporary rather than stable [21], it plays an important role in the general donation experience of FTD and was strongly affected by deferral.

The satisfaction with social aspects of the donation process was worse in deferred versus non-deferred FTD. We assume 3 reasons that may have caused this difference. First, deferred FTD could have experienced lower values of satisfaction because they did not experience crucial social aspects of donation, like communication with staff during and after donation or a refreshment service. The only social interaction they experienced was the deferral situation. Second, deferred FTD could have been unsatisfied with how they got deferred (in relation to manner and/or content). Third, in our sample, mood after deferral was positively correlated with satisfaction with social aspects of the donation process $(r=0.390)$.
The decreased mood in deferred FTD is probably the reason for the lower rates of satisfaction with the social processes; being deferred by a member of the donation staff might feel as a threat to a donor's personal self-esteem and can cause negative feelings, such as hurt [26]. As Richman and Leary [27] illustrate, hurt is a distinct negative emotion that is directly associated with feeling devalued, unwanted, and rejected. It is possible that deferred FTD devaluated the interaction with donation staff in order to protect their self-esteem. Still, the majority of deferred and non-deferred FTD was satisfied or totally satisfied with processes in the donation center. This lack of variance hinders detection of effects. Even though satisfaction was not a predictor of return behavior in our study, satisfaction with social aspects of the donation was also strongly affected by deferral.

The impact of deferral on mood and satisfaction with social aspects of the donation process was observed in both the first and the second path models. This result leads to the assumption that the decrease in mood and satisfaction with social aspects of blood donation is deferral related and independent from the level of donation experience. However, it was not associated with return behavior either in the first or in the second path model.

Due to a power problem, we did not exactly learn from our data why deferred FTD return less often for a second donation than non-deferred donors. In addition, significant zero-order correlations are not robust due to the high intercorrelation of the potential predictors. This fact was considered in the path analyses. Within these, age could be identified as a predictor. Building on findings in older adults who reported a greater increase in hurt feelings following rejection compared to younger adults in another (non-blood donation-related) study [24], it might be possible that age influences the extent to which the level of mood decreases and makes a deferral worse. However, the mean age of our sample was rather low, with approximately $80 \%$ of the participants being younger than 30 years, which limits any definite conclusions. Masser et al. [28] conducted a large study about the impact of age on FTD return behavior. They found a general U-shaped trend as a function of age for returning donors, with younger and older donors having higher odds of returning relative to middle-aged donors. In our study, both returning and non-returning FTD showed an age distribution similar to a hyperbola. The difference between the 2 studies may be explained by the general lack of older FTD in our sample and should be further studied.

Nevertheless, age cannot be the only potential predictor of return behavior. We assume that the decision to return for another donation attempt is based on multiple factors that influence each other. Therefore, it seems promising to investigate numerous potential predictors and the process of decision making together in a study 
with a higher power. As donating blood seems to have affective ramifications, mapping donation behavior via health behavior models and including affective dimensions like momentary mood or specific emotions might be helpful. Further studies on the impact of deferral on return behavior could implement the transtheoretical model of health behavior change [29] which has already proved useful in relation to blood donation behavior [30, 31].

Finally, using a mixed-methods approach would help to gain a deeper understanding of the potential interaction between mood and satisfaction, depending on a deferral and/or the level of donation experience.

\section{Implications}

Our findings could inspire interventions that buffer the impact of deferral and include informational and emotional support. Furthermore, strategies of how to become eligible for donation again should be highlighted, for example, in the form of a small booklet on the causes and consequences of deferral and how to prevent it. Inand out-center retention interventions should be designed based on the needs of the target group and should relate to the social aspects of donation.

Another promising intervention would be an out-center eligibility screening. In Germany, donors need to make the effort to come to the donation center and may receive an in-center deferral that happens in a direct faceto-face interaction with staff. Like in many other blood donation systems (e.g., Australia), it may be more convenient for German donors to participate in an out-center eligibility screening via communication technologies. An out-center screening is applicable for a bigger part of deferral reasons. In case of a deferral, this strategy provides many benefits, such as saving time or effort to go to the donation center and maybe preventing the feeling of being rejected as a person.

Last of all, Suemnig et al. [32] found that one of the key motivators for a first blood donation is the desire to help others. It should be investigated whether this motive gets frustrated in case of a deferral and whether this potential frustration may cause the decreasing mood in deferred FTD. If so, alternative altruistic in-center behaviors (e.g., donating blood for research [33]) that may reduce the frustration of not being able to donate blood should be tested.

\section{Limitations}

In addition to the general limitations of pilot studies, the 2 groups of deferred and non-deferred FTDs were unequally distributed with regard to group size. Additionally, we did not assess further information about the enrolled group of non-genuine FTD. Furthermore, we did not investigate whether there was a significant difference in FTD who participated in this study and FTD who were not willing to participate. We also do not know whether donors who did not return to the blood donation center at University Medicine Greifswald within 12 months did donate blood at another blood donation center in the meantime. Finally, donation-specific satisfaction was assessed using 8 items created for this study. The content of those items was created by analyzing the donation process, yet there is a lack of qualitative and quantitative prestudies to develop the instrument properly. This lack may cause an inadequacy of assessment. A blood donor satisfaction questionnaire has recently been developed and published [34], which might be better suited for a multicenter study. Finally, satisfaction with different aspects of the donation process should be assessed with a comparable reference. For instance, non-deferred FTD experience a different quality and quantity of social contacts within the donation process compared to deferred FTD.

\section{Conclusion}

Our findings suggest that momentary mood and satisfaction with the donation process play an important role within a deferral, even though they did not have a direct impact on return behavior. Our pilot study is one of the first to investigate the impact of deferral on FTD. It seems promising to combine variables from existing health behavior models with affective variables in further studies of this donor group. Future research will focus on how to increase the return rates of deferred FTD once they become eligible again.

\section{Acknowledgment}

We want to thank all of the FTD who participated in our study. Furthermore, we appreciate the support of the staff of the blood donation center at University Medicine Greifswald who helped us realize this study. Finally, we would like to thank Barbara Masser for her feedback on earlier versions of this paper.

\section{Statement of Ethics}

The authors have no ethical conflicts to disclose. This study was approved by the Ethics Committee of University Medicine Greifswald, and all of the participants provided written informed consent in compliance with the Helsinki Declaration.

\section{Conflict of Interest Statement}

The authors have no conflict of interests to declare. 


\section{Funding Sources}

This work was internally funded by University Medicine Greifswald and the University of Greifswald and did not receive external funding.

\section{Author Contributions}

K.G., A.G., H.M., A.S., and S.S. conceived the idea of this study and conducted this study. K.G., H.M., and S.T. analyzed the data. K.G. drafted this paper and created the tables. K.G. and S.T. created the figures. All of the authors revised and approved the final version of this paper for publication.

\section{References}

1 Greinacher A, Weitmann K, Schönborn L, Alpen U, Gloger D, Stangenberg W, et al. A population-based longitudinal study on the implication of demographic changes on blood donation and transfusion demand. Blood Adv. 2017 May;1(14):867-74.

2 Greinacher A, Fendrich K, Hoffmann W. Demographic changes: the impact for safe blood supply. Transfus Med Hemother. 2010 Jun; 37(3):141-8

3 Currie CJ, Patel TC, McEwan P, Dixon S. Evaluation of the future supply and demand for blood products in the United Kingdom National Health Service. Transfus Med. 2004 Feb;14(1):19-24.

4 Bundesärztekammer. Richtlinie zur Gewinnung von Blut und Blutbestandteilen und zur Anwendung von Blutprodukten (Richtlinie Hämotherapie). 2017;103. Available from: http://www.bundesaerztekammer.de/filead$\mathrm{min} /$ user_upload/downloads/pdf-Ordner/ MuE/Richtlinie_Haemotherapie_2017.pdf.

5 Bashawri LA. A review of pre-donation blood donor deferrals in a university hospital. J Family Community Med. 2005 May;12(2): 79-84.

6 Al Shaer L, Sharma R, AbdulRahman M. Analysis of blood donor pre-donation deferral in Dubai: characteristics and reasons. J Blood Med. 2017 May;8:55-60.

7 Custer B, Schlumpf K, Simon TL, Spencer BR, Wright DJ, Wilkinson SL; NHLBI Retrovirus Epidemiology Donor Study-II (REDS-II). Demographics of successful, unsuccessful and deferral visits at six blood centers over a 4-year period. Transfusion. 2012 Apr;52(4): $712-21$.

8 Ngoma AM, Goto A, Sawamura Y, Nollet KE, Ohto H, Yasumura S. Analysis of blood donor deferral in Japan: characteristics and reasons. Transfus Apheresis Sci. 2013 Dec;49(3):65560.

9 Gonçalez TT, Sabino EC, Schlumpf KS, Wright DJ, Mendrone A, Lopes M, et al.; NHLBI Retrovirus Epidemiology Donor Study-II (REDS-II), International Component. Analysis of donor deferral at three blood centers in Brazil. Transfusion. 2013 Mar; 53(3):531-8.

10 Davison TE, Masser BM, Gemelli CN. Deferred and deterred: a review of literature on the impact of deferrals on blood donors. ISBT Sci Ser. 2019;15(1):1-8.
11 Piliavin JA. Temporary deferral and donor return. Transfusion. 1987 Mar-Apr;27(2):199200.

12 Custer B, Chinn A, Hirschler NV, Busch MP, Murphy EL. The consequences of temporary deferral on future whole blood donation. Transfusion. 2007 Aug;47(8):1514-23.

13 Custer B, Schlumpf KS, Wright D, Simon TL, Wilkinson S, Ness PM; NHLBI Retrovirus Epidemiology Donor Study-II. Donor return after temporary deferral. Transfusion. 2011 Jun;51(6):1188-96.

14 Schreiber GB, Sharma UK, Wright DJ, Glynn SA, Ownby HE, Tu Y, et al.; Retrovirus epidemiology donor study. First year donation patterns predict long-term commitment for firsttime donors. Vox Sang. 2005 Feb;88(2):11421.

15 Masser B, Ferguson E, Merz EM, Williams L. Beyond description: The predictive role of affect, memory, and context in the decision to donate or not donate blood. Transfus Med Hemother. 2020 Apr;47(2):175-85.

16 Hinrichs A, Picker SM, Schneider A, Lefering R, Neugebauer EA, Gathof BS. Effect of blood donation on well-being of blood donors. Transfus Med. 2008 Feb;18(1):40-8.

17 Jansen P, Sümnig A, Esefeld M, Greffin K, Kaderali L, Greinacher A. Well-being and return rate of first-time whole blood donors. Vox Sang. 2019 Feb;114(2):154-61.

18 Gemelli CN, Thijsen A, van Dyke N, Masser BM, Davison TE. Emotions experienced when receiving a temporary deferral: perspectives from staff and donors. ISBT Sci Ser. 2018;13(4):394-404.

19 Bednall TC, Bove LL. Donating blood: a metaanalytic review of self-reported motivators and deterrents. Transfus Med Rev. 2011 Oct; 25(4):317-34.

20 Devine D, Goldman M, Engelfriet CP, Reesink HW, Hetherington C, Hall S, et al. Donor recruitment research. Vox Sang. 2007 Oct; 93(3):250-9.

21 Steyer R, Schwenkmezger P, Notz P, Eid M. MDBF Mehrdimensionaler Befindlichkeitsfragebogen. Der Mehrdimensionale Befindlichkeitsfragebogen (MDBF). Goettingen: Hogrefe; 1997.

22 Corp IB. IBM SPSS Statistics for Windows, Version 22.0. Armonk (NY): IBM Corp.; 2013.
23 Muthén LK, Muthén BO. Mplus User's Guide (1998-2015). 7th ed. Los Angeles (CA): Muthén \& Muthén; 2015.

24 Schreiber JB, Nora A, Stage FK, Barlow EA, King J. Reporting structural equation modeling and confirmatory factor analysis results: A review. J Educ Res. 2006;99(6):323-38.

25 Cheng Y, Grühn D. Age differences in reactions to social rejection: The role of cognitive resources and appraisals. J Gerontol B Psychol Sci Soc Sci. 2015 Nov;70(6):830-9.

26 Leary MR. Emotional responses to interpersonal rejection. Dialogues Clin Neurosci. 2015 Dec;17(4):435-41.

27 Smart Richman L, Leary MR. Reactions to discrimination, stigmatization, ostracism, and other forms of interpersonal rejection: a multimotive model. Psychol Rev. 2009 Apr; 116(2):365-83

28 Masser BM, Wright S, Germain M, Grégoire Y, Goldman M, O’Brien SF, et al.; Biomedical Excellence for Safer Transfusion (BEST) Collaborative. The impact of age and sex on firsttime donor return behavior. Transfusion. 2020 Jan;60(1):84-93.

29 Prochaska JO, DiClemente CC. Stages of change in the modification of problem behaviors. Prog Behav Modif. 1992;28:183-218.

30 Sardi L, Idri A, Carrillo de Gea JM, Toval Á, Fernández-Alemán JL. Applying trans-theoretical model for blood donation among Spanish adults: a cross-sectional study. BMC Public Health. 2019 Dec;19(1):1724.

31 Amoyal NR, Robbins ML, Paiva AL, Burditt C, Kessler D, Shaz BH. Measuring the processes of change for increasing blood donation in black adults. Transfusion. 2013 Jun; 53(6):1280-90.

32 Suemnig A, Konerding U, Hron G, Lubenow N, Alpen U, Hoffmann W, et al. Motivational factors for blood donation in first-time donors and repeat donors: a cross-sectional study in West Pomerania. Transfus Med. 2017 Dec;27(6):413-20.

33 Waller D, Thijsen A, Garradd A, Hayman J, Smith G. Donating blood for research: a potential method for enhancing customer satisfaction of permanently deferred blood donors. Blood Transfus. 2017 Jan;15(1):13-9.

34 Trovão AC, Zucoloto ML, Martinez EZ. Development of a blood donor satisfaction questionnaire (BDSQ). Hematol Transfus Cell Ther. 2020 Oct - Dec;42(4):333-40. 